\title{
Gender and Racial Differentials in the Nigerian Banking Industry
}

\author{
Akindele Richard Iyiola (Ph.D) \\ Department of Management and Accounting, Obafemi Awolowo University \\ Ile-Ife, Osun State, Nigeria \\ E-mail: akinrichard@yahoo.com
}

Received: December 17, 2010 Accepted: August 4, 2011 doi:10.5539/ijbm.v6n9p228

\begin{abstract}
The prime focus of this study is to evaluate gender cultures in the Nigerian Banking Industry. The objective of the study is to identify gender cultural indices as to determine their impacts on employee's performance. Major findings of this research work include (1) it was revealed that gender cultures hinder performance of employees (at the .05); and (2) Banks prefer to employ young ladies to married women. These young ladies were employed on temporary basis and are laid off when they cannot meet their targets. Based on the findings, it was recommended that banks should guide, monitor and discourage gender cultures from growing. Abilities should be rewarded irrespective of sex. Conducive working atmosphere should also be created. It was concluded that gender cultures have negative impact on performance.
\end{abstract}

Keywords: Evaluation, Gender, Culture, Performance and Nigerian banking industry

\section{Introduction}

Racial differentials are connected with one's race, or with the different races of people. It is the amount of difference between people or things, especially difference in wages between workers at different levels in the same industry. In Nigeria most especially in the banking industry the phenomenon is very synonymous to racial differentials. Men and women are treated differently in the type of what they do, the department they work with and even what they get at the end of the day. Females are mostly connected with the marketing department, sourcing for either deposits or the prospective shear buyers. Most often they are given target to be met, and in cases where such are not met it leads to termination of appointment. Proofs abound that females are given condition of marriage and even when to give birth, whereas their male counterparts have no restriction. Peradventure females composition and the psychology behind the facts that they are more persuasive and are generally listened to have turned Nigerian females bankers to be hawkers.

In fact, the issue of male-female differences in the Nigerian organizations is now becoming issue of concern for personnel managers, industrial psychologists, investors, politicians and businessmen, because gender awareness is becoming pronounced. According to Hyde, (1981), William and Bedward (2001) there are no consistent male-female differences in problem-solving ability, analytical skills, competitive drive, motivation, sociability, or learning ability. While psychological studies have found that women are more willing to conform to authority, and that men are more aggressive and more likely than women to have expectations of success.

The perspective from which this researcher starts is that gender is a crucial organizing factor within work. Gender stereotypes influence jobs that people do, the pay and conditions associated with those jobs, and the opportunities available to the incumbents of those jobs. Given the significant changes that have taken place in the last twenty years in Nigeria in terms of increasing female participation rates in the work force and rethinking what constitutes male and female roles, one should operate on the belief that there is no significance difference in job productivity between males and females.

This research work identifies the deterrents to the effective functioning of women, and more importantly, generates practical solutions to create pathways for the effective utilization of all human resources. This study is to find out empirically the relationship between gender and racial differentials in the Nigerian banking industry.

\section{Problem and Objectives}

In most countries, particularly, African states, Gender discrimination is more prominent at work; Hunt (1975), Curran (1985) and Thorpe (2005) in their studies confirm that there is a strong evidence of discriminatory behaviour in the work place. Currently in Nigeria, women constitute less than $5 \%$ of the Government Ministers, Senior Military Officers. Even, in occupations in which women predominate such as primary school teaching, they tend to miss out in the senior job. Further still, Morrison and Von Fitinow contended that there is "glass ceiling issue" which emanates from societal prejudice against women that it tends to prevent even the best of women from getting to the peak of their career (Morrison and Von Fitinow, 1990). If it is so, the bone of contention in this 
research work is to find out the relationship between gender and racial differentials on employee's performance in the Nigerian banking industry. The prime focus of this study is to have an evaluation of the relationship between gender and racial differentials of employees in the Nigerian banking industry in order to ascertain it effects on workers' performance. To achieve this, the following specific objectives are pursued:

(i) To identify the components of gender cultures in the banking industry.

(ii) To determine the relative effect of gender cultures on performance of workers

\section{Literature Review}

Scholars have produced hundred of definition s of "culture". Hosfsted's (1984), Ali (2003) and Thorpe (2005) definition is perhaps the best know to management scholars and is used here.

Culture is the collective programming of the mind, which distinguishes the members of one human group from another. Culture, in this sense, includes systems of values; and values are among the building blocks of culture. This implies that:

- A culture is particularly to one group and not others;

- It influences the behaviour or group members in uniform and predictable ways;

- It is learned, and is not innate. It is passed down from one generation to the next;

- Culture includes systems of values.

The first point raised above is that a culture is particular to one special group and not others. This means that: -

- Different social groups have different cultures

- Different social groups may respond to similar situations in different ways.

- The second point raised is that their culture influences the behaviour of members in uniform and predictable ways. This means that, to the extent that you understand the other culture, you can reasonably predict the behaviour of its embers in routine situations

\section{Culture is learned}

The third implication of Hofstede's definition is that our culture is not programmed into our genetic structure. We learn it. In the case of a national culture, we learn most intensively in the early years of life. By the age of five we were already an expert in using our language. We had internalised values associated with such functions as: Interacting with other members of our family, Eliciting rewards and avoiding punishments, Negotiating for what you wanted, Causing and avoiding conflict. Other members of the culture group pass on these values to us. These include parents, adults, family, institutions such as schools, and friends.

\section{Gender Cultures}

Gender cultures tend to reflect two different attitudes to women and men's similarities or differences. Traditional cultures, as seen in the 'Gentleman's Club', the 'Locker Room' and the Barrack Yard, all reflect the view that men and women are fundamentally different and have different roles in society. More recent cultures as witnessed in the Gender Blind, the Smart Macho and the Pretenders, show how the dynamics of gender relations persists even when participants proclaim men and women equal and no difference in their capabilities. This polarization of views was acknowledged by suffragettes and reformers in the $19^{\text {th }}$ century and the persists even today. A more gender-sensitive perspective would acknowledge that women are different in the actual condition of their lives and in many characteristics, but in others are similar they would assert that women's voice, views and rights should not in any case be dependent on their similarity or otherwise with men. The sole reason for this enduring dichotomy is because women and others have feared that women were not acceptable in the public arena unless they were like men. American feminism and women's ways in management affirm this belief (Gordon, 1991) and (Degroot, 2001)

Men and women in more traditional cultures assume that the differences between them are natural and ordained and in Britain they hanker after a Janet and John type land, where the woman does the chores and cares for her children, whilst her partner earns the money. For many men used to such a clear-cut division, encountering women at work can be unsettling, if not disturbing.

The experience of women in the world of work is a topic of unparalleled importance in the field of management and yet few books have appeared either in the European academic or business spheres, addressing the area (Osborne, 1993). Osborne augured that women represent more than half of the world's population and their representation in organizations are very different from those of men. In the past, researchers have either tended to assume a commonality - that what is true of the experience of men at work will be true of women - or have used only male subjects. It is only more recently women's experiences are being examined (Morse 1993) and (Silvery 2000). Jenny and Michael (1993) reiterated that there is a growing movement towards examining the experiences of women in organisations in their own right, in order that a fuller, more accurate picture can be painted.

Corporate managers can play a significant part in creating 'gender cultures' and gender dynamics (CMPS Audits, 1992-3). Although there are common themes, each organization has its own brand of leadership and its own 
characteristic work culture, and each in turn develops its own peculiar resistance to equally proposals. The lack of attention to the spirit, informal norms and values of an organization has led to many equality programmes being sabotaged by both management and mal and female staff. Equality audits reveal that some gender cultures are understood to reflect a natural order, illustrated by the Gentleman's Club, in which women feel valued if they conform to female stereotypes. The Barrack Yard and the Locker Room are more authoritarian versions of the Gentleman's Club, where men and women's collusion is out of fear as well as being based on a cultural agreement.

In organizations where there is an acceptance of women in the workplace and an acceptance that women have a right to promotion, culture develop where 'lip service' is paid toward equality, or perhaps a more positive environment develops where women are judged on merit and in their own right. The Gender Blind and the Smart Macho cultures acknowledge the justice of equality but ignore from where disadvantage springs. Corporate rather than natural agendas tend to determine these cultures. Managers in organizations driven by profit and the need for greater efficiency are not interested in sustaining patriarchal power if it conflicts with economic interest. Smart Machos in particular are interested in economics rather than patronage. If barriers to women hinder performance targets then inequalities become a management problem as well as a problem for women. However, the force of the economic argument appears to be influencing executives rather than middle managers, and it is the middle managers and other women who are the 'gate-keepers' for women seeking change. Whilst executives are looking to promote women in middle management, they still protect their exclusive male culture at board level (Handy, 1991), Akindele \& Ologunde (2000) and Akindele (2006).

The Feminist Pretenders are committed to the theory of equality but, in reality, are reluctant to relinquish their power over women. These men are often using women in their own battles with other men. The Feminist Pretenders push women in the direction they want them to go in - the result being that they are often more oppressive than managers in the Gentleman's Club, who leave women alone to get on with their jobs. Too many statements are made in the name of women, when women themselves are often in conflict over how to react to a gendered culture at work. Gender dynamics, frequently unnoticed by men, create psychological walls for women. They are also disastrous for organizations. Not only do they waste women's energy and potential, they also damage and distort communication, which in turn affects performance and productivity - but also that's another story. (Awe, 1990) and Akindele. (2006 \& 2007) Suffice it to say, democratic organizations will only develop when the power of gender cultures is acknowledged and challenged by both men and women.

In the literature there are many theories associated with gender, they are: The Gentleman's Club, the Barrack Yard, the Locker Room, The Gender Blind, The Smart Macho, paying lip service, women as Gate keepers, Glass ceiling theory, Assimilation Model of equality and Masculine Ethic in organizations and barriers of women in organization.

\section{Studies on Job Performance}

A lot of studies have been carried out over the years in an attempt to unravel the possible relationship between job performance and its hypothesized antecedents. Traditionally, personnel managers or psychologists have assumed that performance in large part is a function of selection placement training and job design.

Performance - $\mathrm{f}$ (Ability x motivation). Campbell and Prilchard, (1976) posited that the formulation of this has been widely adopted in its original form and with minor modifications, its capability to "account form additional variance in performance has been singularly unsuccessful". However, the shortcomings of the formulation become obvious when an attempt is make to use it to organize what is known about performance. If the formulation is correct and complete, then each of the many variables that affect performance should be capable of being subsumed under dimension of ability or that of motivation.

More so, Charles, and Blumberg (1986) opined that, for high job performance of the place opportunity, capacity and willingness must be present.

They presented this idea as an equation:-

$$
\mathrm{p}=\mathrm{f}(\mathrm{o}, \mathrm{c}, \mathrm{w})
$$

The equation says that performance (p) is a function (f) of three interacting categories-opportunity (o) capacity (c) and willingness $(\mathrm{w})$. They further highlighted that if any of these categories is missing or has a low value, the performance will not occur or will occur at a very low level. These they explained further using an analogy; one of the authors visited a coalmine production. A major care in had occurred and even the most capable and willing miners could not produce any coal until it was cleared. Hence opportunity was zero. Similarly, a novice miner who has not yet been trained to mine, might have high willingness and might be given the opportunity to substitute for an experienced, mine who is sick. The novice, however, will mine little coal because his or her capacity (i.e, ability and knowledge) will be low. Finally, miners who go out on strike illustrate the cause of individuals who have the capacity to perform and the opportunity (i.e. management leaves the mine open), yet do not have the requisites willingness; hence not coal production occurs. However, the interaction of the three dimensions opportunity willingness and capacity are perceived by Charles and Blumberg (1986), Akindele, Nassar and Adetayo (1999) and Akindele (2006) to inevitable before any successful, performance could be attained. In addition to the most studied antecedents of job performance, are leadership job satisfaction, job attitude, motivation, personality and a 
host of others.

\section{Research Methodology}

The study employed a $2 \times 2 \times 2$ factorial design and it involved a descriptive survey method and multistage sampling techniques. Information was gathered from respondents through close-ended structured questionnaires and interview. The population for this study was employees of all the banks in Nigeria. Since the research has a multistage sampling technique eight selected banks were used finally as the target population. All banks were stratified into: old and new generation. Consequently four banks were chosen from each strata; four old namely: First Bank, Union Bank, Afri Bank and Cooperative Bank and four new generation Banks namely: Zenith, Prudent, Chartered Bank, Global Bank.

The population of the study was estimated to about six thousand work force. Random sampling technique was used for the selection of the respondents. Six hundred and sixty (660) respondents were selected from and among the employees of the selected banks, eighty (80) from each of the eight selected banks and they were the one that filled the questionnaires. Invariably three hundred and forty-six (346) questionnaires were retrieved while three hundred (300), $90 \%$ were regarded as valid and useable and became the final sampling size for the study. However, Heads of six (6) units and four (4) employees from marketing department were those selected for the interview. Information gathered from the questionnaire was later analyzed with the aid of descriptive statistics via sum total, means, minimum scores, standard deviation, standard errors and variance, while analysis of variance (ANOVA) was used as inferential statistics; to compared gender culture indices i.e socio-cultural, look worm attitude of women, inbuilt organizational structure, lack of support from the family, lack of self confidence marriage responsibility, male hostility and female over protection, with performance indices such as quality of work, productivity, accident reduction, knowledge of the job, tenure, attitude, absenteeism, mastery of the job, co-operation and individualism as shown in table 1 (see appendix)

From table 1, comparing the mean scores; Lack of support from the family had the highest means while inbuilt organizational structure had the lowest. This shows that a relationship exists between gender variables and that they affect performance. To actually know the one that effects performance most, one-way analysis of variance (ANOVA) was implored as shown in table 2 (see appendix)

From table 2 (ANOVA) (see appendix), the result is as follows: - Inbuilt organizational structure as an index of (F $=.760$, Sig. at .384, (.05 level of freedom) which means, gender culture affects employees performance in the Nigerian Banking Industry, than other indices. Followed by Marriage Responsibility ( $F=1.562$, at sig. of 0.212 $(.05$ level freedom)), followed by Male hostility $(\mathrm{F}=3.030$, at sig. of $0.082(.05$ level of freedom)), followed by Lack of self confidence $(\mathrm{F}=4.943$, sig. at 0.027 ( .05 level of freedom) ) and in that other. The result from table 2 showed that relationships exist between gender cultures that is already in existence among the employees in the Nigerian banking industry and performance.

From the analysis from table 1 and 2 . The two hypotheses were rejected and that a significant relationship exists.

\section{Summary, Conclusion and Recommendations}

It is of interest to note that the indices for gender cultures affected employees' performance within the Nigerian banking industry. It is note worthy, that the interest of this work is to see the effect of indices of the gender cultures on one another and see how they interact on short and long run and their effect on worker's performance. Also, how will gender that is, male and female affect our level of reasoning and judgment with regard to the gender cultures in the banking industry? This work provides ready-made answer to the question posed.

\section{Summary}

The empirical results show that a relationship exists between gender cultures in the Nigerian Banking Industry and employee performance. It was found that, Inbuilt Organizational Structure as an index of gender culture affects employee performance in the Nigerian Banking Industry, than other indices followed by Marriage Responsibility, thirdly by Male hostility, fourthly by Lack of self-confidence and in that other.

It was evident that gender cultures affected employee performance considerably. From the result of the interview women who were transferred compulsorily to rural banks as manager or accountant told the researcher that they were discriminated against and that they would have love to stay with their family in the city and even as a signatory A "Officer". The relationship between gender cultures and employee performance that was established shows that; gender cultures by one way or the other hinders employee performance. It means then that if gender culture is buried and reduced to the bear-rest minimum employee's performance could be improved upon.

\section{Conclusion}

It is apparent from the study that women no matter how few, generally occupy male-dominant environments since their bosses; colleagues and subordinates are all more likely to be men than women. In particular, women are highly likely to have a male boss and highly unlikely to have a female boss, showing how much the women manager remains under the control of men at work. This suggests that employers may be reluctant to hire women to supervise men and may prefer to hire a woman to manage other women in traditionally female role areas. Other explanations are that women are more likely to hire other women to work for them and that men are reluctant 
to apply for a job in which a woman is the boss.

\section{Recommendations}

The following recommendations were on the basis of the findings that emanated from this study: That people's ability and output should be rewarded irrespective of the gender of the worker and reward or motivation should not be tied down to gender but individual dispositions. Also promotion should not be based on sex but rather the individual's contribution to the achievement of the organizational goals. Finally, on the employment of labour and promotion, the job should be given to who can do it, not necessarily the gender of the work holder.

\section{References}

Akindele R. I. (2006). Impact of Gender Cultures and Motivation on Performance of Workers within the Banking Industry in Lagos State of Nigeria. $\mathrm{PhD}$ thesis, Department of Business Administration University of Ilorin.

Akindele R.I. (2007). Fundamentals of Human Resources. Cedar Publications, Ile- Ife. Nigeria. (416)

Akindele R.I., \& Ologunde A.O. (2000). An Appraisal of the Management of Industrial Disputes of the Local Government Level. Ife Social Sciences Review, Vol. 18 No. 1 pp. 207-219.

Akindele R.I., and Ologunde A.O. (2000). Gender Factor in Work Organisation: Osun State Situation. Journal of Nigerian Anthropological and Sociological Association, O.A.U. Ile-Ife.

Akindele R.I., Nassar, M.L., and Adetayo J.O. (1999). Performance and Leadership styles in Nigerian Manufacturing Industry. Ife Social Sciences Review, vol. 17 No. 2 pp.

Ali. S. (2003). 'To be a Girl': Culture and Class in Schools. Gender and Education, Vol 15 No 3, Sept; Pp 269-283. doi:10.1080/09540250303859, http://dx.doi.org/10.1080/09540250303859

Awe, B. (1990). The Role of Nigerian Women in Management in the 90's in Management in Nigeria. Vol. 26 No. 6 pp. 8-11.

Degroot G.J. (2001). A Few Good Women: Gender Stereotypyes, the Millitary and Peace Keeping. International Peace Keeping, Vol.8 No 2 Pp 23-38.

Epstein, Cynthia F. (1976). Sex role stereotyping, occupations and social exchange. Women's studies, 3: 185-94.

Epstein, Cynthia F. (1985). Ideal Roles \& Real Roles or the fallacy of the misplaced Dichotomy. Research in social stratification and mobility, 4: 29-51.

Gordon, S. (1991). Prisoners in the Man's Dream: Striking out for a new Feminine future. Little Brown \& Company, Boston.

Hunt, J. (1982). "A woman's place is in her Unions" in J. West (ed). Work, Women and the labour Market London: Rontledge \& Kegan Paul.

Hunt. P. (1980). Gender and Class Consciousness. London: Macmillan.

Huse, E. F \& J. L. Bowditch. (1977). Behaviour in Organisation Systems: Approach to a Management, $2^{\text {nd }}$ Ed. Reading Mass: Addison Wesley Publishing Co.

Hyde, J. (1981). Half the Human experience: The Psychology of women. Lexington, Mass D.c Health, Game and Pringle, (1984).

Hyde. (1981). How large are cognitive gender differences? American Psychologist, Oct. pp. 892-901.

Morse, J. J. (1975). Organisation and Their Memoers: A Contingency Approach. New York: Harper and Row Press.

Ray-Mazuinder S. (2001). Role of Gender, Insurance Status and Culture in Attitudes and Behavior in a US Chinese Student Population. Ethnicity and Health, Vol 6, No 3\&4 Pp 197-209. doi:10.1080/13557850120078125, http://dx.doi.org/10.1080/13557850120078125

Silvery R.M. (2000). Stigmatized Spaces: gender and mobility under crisis in South Sulawesi, Indonesis. Gender, Place and Culture-A Journal of Feminist Geography, Vol 2 No 2 June. Pp. 143-161.

Steinhoff, P.G., \& Tanaka, K. (1986). Fall (Winter): Women Managers in Japan. International studies of Management and Organisation, 16, 108-132.

Thorpe, Holly. (2005). Jibbing the gender Order: Females in the Snowboarding Culture. Sport in Society, Vol 1 No1 March. Pp75-100.

Williams A \& Bedward J. (2001). Gender, Culture and Generation Gap: Student and Teacher Perceptions of Aspects of National curriculum physical. Sport, Education and Society, Vol 6, No 1, pp 53-66. 
Table 1. Descriptive statistics of relationship within gender cultures and compared with performance variables of employees in the Nigerian Banking Industry

\begin{tabular}{|c|c|c|c|c|c|c|c|}
\hline Indices & \multicolumn{2}{|c|}{$\mathrm{N}$ Minimum } & \multicolumn{2}{|c|}{ MaximumSum } & \multicolumn{2}{|c|}{ Mean } & Std. Deviation \\
\hline Indices & Statistic & Statistic & Statistic & Statistic & Statistic & Std. Error & Statistic \\
\hline Socio cultural & 300 & 6.00 & 15.00 & 3233.00 & 10.7767 & .1360 & 2.35626 \\
\hline Look worm attitude of $\mathrm{w}$ & 300 & 6.00 & 49.00 & 3379.00 & 11.2633 & .1870 & 3.23867 \\
\hline Inbuilt org. structure & 300 & 5.00 & 64.00 & 2778.00 & 9.2600 & 2539 & 4.39813 \\
\hline Lack of support - family & 300 & 6.00 & 15.00 & 3380.00 & 11.2667 & .1283 & 2.22232 \\
\hline Lack of self confidence & 300 & 6.00 & 15.00 & 2930.00 & 9.7667 & 1461 & 2.53119 \\
\hline Marriage responsibility & 299 & 5.00 & 15.00 & 3221.00 & 10.7726 & . 0940 & 1.62462 \\
\hline Male hostilities & 300 & 6.00 & 15.00 & 2876.00 & 9.5867 & .1185 & 2.05179 \\
\hline Female over protection & 300 & 5.00 & 15.00 & 3061.00 & 10.2033 & .1285 & 2.22527 \\
\hline Performance variables & 300 & 39.00 & 84.00 & 12641.00 & & & \\
\hline Valid N (list wise) & 299 & & & & & & \\
\hline
\end{tabular}

Source: Fieldwork 2006

Table 2. One-way analysis of variance (ANOVA) to show the relationship between gender cultures and performance variables

\begin{tabular}{|l|l|l|l|l|l|l|}
\hline \multicolumn{1}{|c|}{ Indices } & & Sum of Squares & df & Mean Square & F & Sig. \\
\hline & Between Groups & 61.673 & 1 & 61.673 & 11.498 & .001 \\
\hline & Within Groups & 1598.364 & 298 & 5.364 & & \\
\hline & Total & 1660.037 & 299 & & & \\
\hline & Between Groups & 26.275 & 1 & 26.275 & 2.518 & .114 \\
\hline & Within Groups & 3109.922 & 298 & 10.436 & & \\
\hline & Total & 3136.197 & 299 & & & \\
\hline Inbuilt org. structure & Between Groups & 14.711 & 1 & 14.711 & .760 & .384 \\
\hline & Within Groups & 5769.009 & 298 & 19.359 & & \\
\hline & Total & 5783.720 & 299 & & & \\
\hline Lack of support - family attitude of $\mathrm{w}$ & Between Groups & 28.111 & 1 & 28.111 & 5.783 & .017 \\
\hline & Within Groups & 1448.555 & 298 & 4.861 & & \\
\hline & Total & 1476.667 & 299 & & & \\
\hline Lack of self confidence & Between Groups & 31.259 & 1 & 31.259 & 4.943 & .027 \\
\hline & Within Groups & 1884.407 & 298 & 6.324 & & \\
\hline & Total & 1915.667 & 299 & & & \\
\hline Marriage Responsibility & Between Groups & 4.115 & 1 & 4.115 & 1.562 & .212 \\
\hline & Within Groups & 782.420 & 297 & 2.634 & & \\
\hline & Total & 786.535 & 298 & & & \\
\hline & Between Groups & 12.753 & 1 & 12.753 & 3.050 & .082 \\
\hline Male hostility & Within Groups & 1245.994 & 298 & 4.181 & & \\
\hline & Total & 1258.747 & 299 & & & \\
\hline & Between Groups & 51.492 & 1 & 51.492 & 10.737 & .001 \\
\hline Female over protection & Within Groups & 1429.104 & 298 & 4.796 & & \\
\hline & Total & 1480.597 & 299 & & & \\
\hline & Between Groups & 44.113 & 1 & 44.113 & 4.575 & .033 \\
\hline Performance & Within Groups & 2873.284 & 298 & 9.642 & & \\
\hline & Total & 2917.397 & 299 & & & \\
\hline
\end{tabular}

Source: Fieldwork 2006 .05 level of freedom. 